\title{
Escrita argumentativa em língua espanhola: uma análise discursiva e retórica de artigos de opinião de alunos iniciantes do Curso de Letras/Espanhol
}

\author{
Argumentative writing in Spanish language: a discursive and rhetorical analysis of opinion articles \\ written by students in the beginning of Spanish language learning
}

\author{
Flávia Colen Meniconi \\ Maria Inez Matoso Silveira \\ Universidade Federal de Alagoas - Maceió - Alagoas - Brasil
}

\begin{abstract}
Resumo: Este artigo é fruto de uma pesquisa mais ampla sobre o processo de ensino da escrita argumentativa para alunos iniciantes no aprendizado da língua espanhola. Nosso objetivo foi analisar se o desenvolvimento de uma sequência didática de ensino explícito de estratégias retóricas contribuiria para a produção de artigos de opinião em espanhol. Trata-se de uma pesquisa-ação, de caráter interventivo. $\mathrm{O}$ aporte teórico do trabalho teve como referência as teorias argumentativas de cunho retórico (PERELMAN e TYTECA, 2005, PLANTIN, 2008, REBOUL, 1999; MEYER, 2007) e sociorretóricas (BITZER, 1968; BAZERMAN, 2007). Neste artigo, apresentamos a análise discursiva e retórica de artigos de opinião elaborados pelos participantes da pesquisa. Os resultados revelaram que os alunos são capazes de produzir textos argumentativos em espanhol ainda nas fases iniciais de sua aprendizagem. Tal fato evidencia a importância da sistematização de sequências didáticas de ensino da escrita argumentativa, desde o início da aprendizagem do idioma.
\end{abstract}

Palavras-chave: produção de texto; escrita argumentativa; ensino de espanhol.

\begin{abstract}
This article resulted from a broader research about the teaching of argumentative writing process designed for beginners of Spanish language. Our objective was to analyse if the development of a didactic sequence with explicit teaching of rhetorical strategies would contribute for the production of opinion articles in Spanish. It deals with an action-research, with an interventional character. The theoretical rationale of the work is based on rhetorical argumentative theories (PERELMAN e TYTECA, 2005, PLANTIN, 2008, REBOUL, 1999; MEYER, 2007). In this article, we present a discursive and rhetorical analysis of opinion articles produced by the informant students who participated in the research. The results revealed that the students were able to produce argumentative texts in Spanish even in the beginning of their learning process. This fact emphasizes the importance of systematization of didactic sequences for teaching of argumentative writing since the beginning of the language learning.
\end{abstract}

Keywords: writing process; argumentative writing; Spanish language teaching.

\section{Introdução}

Como professoras de línguas estrangeiras, vimos, há alguns anos, percebendo a grande dificuldade que muitos alunos apresentam em relação à produção escrita em línguas estrangeiras, inclusive em espanhol. Ao analisar os textos dos graduandos de Letras/Espanhol, da Universidade Federal de Alagoas, onde lecionamos atualmente, observamos que os problemas composicionais variam desde as dificuldades relacionadas aos aspectos linguísticos do idioma, até o uso adequado de estratégias discursivas para a elaboração de ideias claras, coesas e coerentes (MENICONI, 2010; 2015).

Antunes (2010) argumenta que a elaboração de um texto requer mais do que o emprego de regras de boa formação de orações e períodos. Para a autora, escrever bem demanda a ativação de conhecimentos linguísticos, conhecimentos de mundo e conhecimentos referentes aos gêneros textuais.

O trabalho com leitura e produção de textos a partir da proposta de gêneros textuais convida-nos a sair do ensino da estrutura gramatical e frasal descontextualizado, e 
adentrarmos no universo do trabalho com o texto enquanto um conjunto de enunciados organizados para expressar intenções comunicativas, negociações, interações sociais, pontos de vista, ideias e emoções.

Dentro desse enfoque, Bakhtin esclarece que quanto melhor dominamos os gêneros tanto mais livremente os empregamos, tanto mais plena e nitidamente descobrimos neles a nossa individualidade (onde isso é possível e necessário), refletimos de modo mais flexível e sutil sobre a situação singular da comunicação; em suma, realizamos de modo mais acabado o nosso livre projeto de discurso (BAKHTIN, 2003, p. 285). Segundo o autor, os gêneros "são tão indispensáveis para a compreensão mútua quanto às formas da língua" (BAKHTIN, 2003, p. 285).

Com a intenção de direcionar o ensino da língua espanhola para uma perspectiva mais discursiva, esta pesquisa desenvolveu uma sequência didática ${ }^{1}$ de ensino explícito de estratégias argumentativas voltadas para a produção de artigos de opinião em espanhol. O artigo de opinião foi escolhido pelo fato de, além de ser um gênero que circula em rádios, televisões, jornais, revistas e internet, tem como objetivo apresentar diferentes posicionamentos com a finalidade de convencer o leitor, espectador ou ouvinte (UBER, 2008). Aspectos relacionados à importância da escrita argumentativa para a produção de artigos de opinião serão discutidos nas seções subsequentes.

\section{As contribuições do ensino-aprendizagem da produção escrita de artigos de opinião em língua espanhola}

Marcuschi (2008) define o artigo de opinião como um gênero da modalidade escrita do domínio discursivo jornalístico, da ordem do argumentar. Esse gênero textual "aborda assuntos polêmicos que circulam na imprensa, na mídia e na sociedade" (FEITOZA; MENDES, 2010, p. 58). Por meio dele, o autor busca a compreensão do leitor em relação ao seu posicionamento diante do tema, isto é, da tese defendida.

Segundo Santos e Melo (2012), o artigo de opinião tem a persuasão como uma característica peculiar. Através desse gênero, o autor busca convencer o leitor a adotar a posição defendida. As autoras ainda argumentam que, por esse motivo, os artigos de opinião apresentam "descrições detalhadas, apelo emotivo, acusações, humor, ironia e fontes de informações precisas" (SANTOS; MELO, 2012, p. 625).

\footnotetext{
Segundo Dolz, Noverraz e Schneuwly (2004), a sequência didática refere-se a "um conjunto de atividades escolares organizadas de maneira sistemática, em torno de um gênero textual oral ou escrito" (DOLZ, NOVERRAZ; SCHNEUWLY, 2004, p. 97).
}

Além disso, está também presente na estrutura do gênero a ocorrência da polifonia, isto é, mecanismos enunciativos que têm por objetivo apresentar vozes advindas de outros textos, além do discurso do próprio autor (BRONCKART, 1999). Na opinião de Feitoza e Mendes (2010), é de fundamental importância chamar a atenção do aluno para a questão da polifonia presente nos textos argumentativos, pois ao "abordá-la no trabalho com o gênero artigo de opinião, o aluno poderá perceber que, na sociedade, há discursos diferentes discutindo sobre o mesmo tema e sob de diferentes pontos de vista" (FEITOZA; MENDES, 2010, p. 58).

Ainda no que diz respeito à característica polissêmica do gênero, Santos e Melo (2012) dizem que "o artigo de opinião, especificamente, é um texto no qual o produtor está a todo instante negociando com as vozes presentes no texto, ora aceitando-as, ora refutando-as e, dessa forma, construindo o seu ponto vista" (SANTOS; MELO, 2012, p.9). A consciência em relação às características polissêmicas do artigo de opinião e o conhecimento sobre o uso de estruturas linguísticas e discursivas para aceitar ou refutar opiniões na produção de textos opinativos são de fundamental importância na escrita argumentativa.

O trabalho com artigos de opinião em sala de aula possibilita ao aluno o contato com discursos diferentes, sobre temas variados, e a observação dos recursos e estratégias argumentativas utilizadas pelos autores, para a construção de suas ideias. Esse trabalho permite a compreensão de que o funcionamento da língua vai muito além do domínio de suas regras gramaticais. $\mathrm{Na}$ argumentação, e em outros tipos de textos opinativos, a escolha das palavras, frases, expressões e as organizações de sequências enunciativas mostram o caráter estratégico, intencional e político do funcionamento da língua. Esses aspectos podem ser trabalhados no ensino da leitura e produção de artigos de opinião e, além do mais, contribuem para a formação crítica do aluno.

A seguir, será apresentado o aporte teórico que fundamentou a sequência didática de ensino-aprendizagem da argumentação e da produção de artigos de opinião.

\section{A argumentação retórica como eixo norteador do processo de ensino da produção escrita de artigos de opinião}

Segundo Perelman e Olbrechts-Tyteca (2005), toda argumentação tem como objetivo "provocar ou aumentar a adesão dos espíritos às teses que se apresentam a seu assentimento" (PERELMAN; OLBRECHTS-TYTECA, 2005, p. 50). A argumentação retórica, por sua vez, tem como finalidade persuadir ou convencer pelo discurso, a partir da fala ou da escrita. Perelman e Olbrechts-Tyteca 
(2005) estabelecem uma diferença entre persuadir e convencer, argumentando que na persuasão acredita-se e se aceitam pressuposições por razões afetivas ou pessoais, sem que seja preciso estar convencido do argumento que se defende. No convencimento, faz-se presente o caráter racional da adesão.

Segundo Reboul (1998), na argumentação retórica, é importante ter em mente que aquele que fala ou escreve nunca está sozinho e "exprime-se sempre em concordância com outros oradores ou em oposição a eles, sempre em função de outros discursos" (REBOUL, 1998, p.XIX). De acordo com o autor, essa é lei fundamental da retórica. Nesse sentido, para ser um bom orador ou escritor, não basta proferir, ler ou escrever; é preciso, antes de tudo, considerar a quem se fala, lê ou escreve, levando em conta os discursos do outro e os seus não ditos (REBOUL, 1998).

Um dos grandes problemas presentes na produção escrita de textos argumentativos está relacionado ao fato de que, muitas vezes, o escritor não leva em consideração o contexto retórico para o qual escreve, isto é, o leitor, os objetivos do seu texto, suas intenções e propósitos comunicativos. Assim como falhas na argumentação lógica podem provocar problemas linguísticos que afetam a compreensão de uma produção textual, deslizes retóricos também podem ocasionar incoerências em relação às intenções comunicativas e posicionamentos que se pretendem defender no texto escrito.

$\mathrm{Na}$ argumentação é também importante conhecer os três tipos de argumento: o ethos, o pathos e o logos. Estes aspectos serão discutidos na próxima seção.

\section{Os três tipos de argumentos: ethos, pathos e logos}

Segundo Reboul (1998), “o ethos é o caráter que o orador deve assumir para inspirar confiança no auditório, pois, sejam quais forem seus argumentos lógicos, eles nada obtêm sem essa confiança" (REBOUL, 2000, p. 48). Cada auditório tem suas peculiaridades, que variam de acordo com a idade, sexo, nível social, profissão, dentre outras. Nesse sentido, o ethos do orador deverá variar de acordo com as características do seu auditório.

O ethos, na verdade, identifica o orador ou o escritor, isto é, a pessoa capaz de responder aos questionamentos do auditório ou do leitor. Segundo Meyer (2007), "o ethos se apresenta de maneira geral como aquele ou aquela com quem o auditório se identifica, o que tem como resultado conseguir que suas respostas sobre a questão tratada sejam aceitas" (MEYER, 2007, p. 35).

O pathos refere-se ao "conjunto de emoções, paixões e sentimentos que o orador deve suscitar no auditório com seu discurso" (REBOUL, 1998, p.48). A paixão em retórica diz respeito ao temor, esperança, ódio, desespero, desejo, isto é, todos os sentimentos presentes no leitor ou auditório. Em relação às questões levantadas pelo escritor, o leitor pode aderir, recusar, completar, modificar, permanecer em silêncio, aprovar, reprovar ou desinteressar-se. Em relação a esta questão, Perelman e Olbrechts-Tyteca (2005) chamam a atenção para o fato de que o auditório do escritor é difícil de ser determinado, pois em grande parte dos casos os leitores não podem ser previstos com exatidão. E, por essa razão, os autores preferem definir o auditório como "um conjunto daqueles que o orador quer influenciar com sua argumentação" (PERELMAN; OLBRECHTS-TYTECA, 2005, p. 22).

A retórica inclui também no discurso, a racionalidade e a linguagem. Essas três características podem ser definidas como logos. Segundo Meyer, o logos "subordina a suas regras próprias o orador e o auditório: ele persuade um auditório pela forma de seus argumentos, ou agrada a esse mesmo auditório pela beleza do estilo, que comove aqueles a quem se dirige" (MEYER, 2007, p. 22).

Considerar o ethos, o pathos e o logos na elaboração do texto argumentativo é de extrema importância, pois leva o escritor a pensar em si mesmo, no leitor e em seu texto de forma consciente e planejada. Na elaboração do artigo de opinião, o escritor não pode deixar de considerar esses elementos, já que precisará reunir argumentos e estratégias retóricas para ser convincente. A seguir, apresentamos a estrutura do artigo de opinião trabalhada na sequência didática.

\section{A estrutura do artigo de opinião}

Boff, Köche e Marinello (2009) argumentam que a produção de um artigo de opinião está pautada na discussão, reflexão, solução e avaliação de um problema. Para tanto, os autores apresentam a seguinte estrutura: 1 - situação-problema; 2 - discussão; 3 - Solução-avaliação.

Na situação problema, apresenta-se a questão a ser desenvolvida com o objetivo de direcionar o leitor em relação ao desenvolvimento das ideias subsequentes. Nessa parte, contextualiza-se o assunto a ser discutido, por meio de afirmações gerais e/ou específicas, com a apresentação do objetivo da argumentação que será sustentada no texto.

$\mathrm{Na}$ discussão, expõem-se os argumentos que sustentam a tese do autor. Nesse momento, são apresentados conceitos, fatos e exemplificações. Segundo Boff, Köche e Marinello (2009), exposições de fatos concretos, dados e exemplos, bem como o emprego de sequências narrativas, descritivas e explicativas são utilizados, na 
discussão, com o objetivo de evitar abstrações. Já na solução- avaliação evidencia-se a resposta apresentada à questão, com a exposição da reafirmação da posição assumida ou apreciação do assunto abordado.

Segundo os autores, a estrutura do artigo de opinião apresentada não é rígida, mas o diferencia de outros gêneros textuais, com a finalidade de "facilitar os encaminhamentos didáticos presentes no seu processo de ensino-aprendizagem" (BOFF; KÖCHE; MARINELLO, 2009, p. 6).

No que diz respeito à produção do artigo de opinião, Santos e Melo (2012) afirmam que a etapa mais complexa da elaboração do gênero é a argumentação, pois para argumentar não basta apenas opinar sobre um determinado assunto. $\mathrm{O}$ texto argumentativo exige também a apresentação das razões que sustentam as ideias defendidas. Nesse sentido, a complexidade da composição do artigo de opinião requer a elaboração de propostas de ensino que contribuam para a aprendizagem da escrita argumentativa, já que para argumentar não basta, simplesmente, conhecer os aspectos linguísticos do idioma. A seguir, apresentamos os procedimentos metodológicos que orientaram o desenvolvimento desta pesquisa.

\section{Metodologia da pesquisa}

A pesquisa foi desenvolvida durante o primeiro semestre do ano de 2013 na disciplina de Língua Espanhola 1, da Faculdade de Letras, da Universidade Federal de Alagoas e teve como participantes 14 alunos. É importante salientar que este artigo é um recorte de uma pesquisa de doutorado realizada durante o período de 2011 a 2015, financiada pelo CNPq.

A investigação caracterizou-se como uma pesquisa-ação, de caráter interventivo, já que objetivou compreender uma dada realidade e nela intervir para, de alguma maneira, modificá-la (THIOLLENT, 1986). Nesta pesquisa, analisamos dificuldades dos estudantes relacionadas à produção de artigos de opinião em língua espanhola, durante o desenvolvimento de uma sequência didática. Como professoras e pesquisadoras, buscamos compreender, mais profundamente, a forma como os alunos estavam vivenciando a sequência didática de ensino-aprendizagem da produção textual e como percebiam as dificuldades oriundas desse processo. Discutimos, conjuntamente, sobre as ações que poderiam ser direcionadas à melhoria dos textos produzidos e desenvolvemos estratégias de ensino-aprendizagem voltadas para evolução da escrita argumentativa em língua espanhola.

$\mathrm{Na}$ sequência didática desenvolvida, trabalhamos com o conteúdo referente aos elementos textuais e retóricos que caracterizam o artigo de opinião. Os alunos aprenderam a analisar o ethos, o pathos e o logos em diferentes artigos de opinião e a utilizar estes elementos em suas produções textuais. Trabalhamos também com o ensino das estratégias argumentativas presentes no artigo de opinião, tais como: a argumentação, a contra-argumentação, a generalizações, os exemplos, entre outras. Como já foi mencionado, o objetivo deste trabalho foi o de levar os alunos a conhecer e utilizar os elementos discursivos e retóricos na produção de artigos de opinião em língua espanhola, nas fases iniciais da sua aprendizagem.

Neste artigo, apresentamos a análise de cinco aspectos presentes nas produções textuais realizadas pelos participantes desta pesquisa, quais sejam: 1 - as características prototípicas do artigo de opinião; 2 - as estratégias argumentativas utilizadas pelos alunos para convencer o leitor, a partir do logos; 3 - as marcas de subjetividade do autor, características do seu ethos; 4 - a forma como o autor interage com o leitor, a partir do pathos; 5 - os elementos polifônicos presentes nos artigos de opinião produzidos pelos alunos. O objetivo desta análise foi o de conhecer a estrutura argumentativa e discursiva dos artigos de opinião produzidos pelos alunos, após a sequência didática desenvolvida.

Para a análise desses elementos, foram escolhidos os três últimos textos do universo de 55 produções textuais realizadas pelos participantes da pesquisa. O critério de escolha baseou-se na seleção de artigos de opinião de alunos que participaram com frequência e assiduidade da sequência didática. A seguir, apresentamos a análise dos aspectos discursivos e retóricos dos artigos de opinião desenvolvidos pelos participantes da pesquisa.

\section{Análise de dados e discussão de resultados}

Os artigos de opinião escolhidos para o desenvolvimento da análise dos aspectos textuais e retóricos versam sobre o tema da profissão docente nos dias atuais. Entre os cinco assuntos propostos para leitura, discussão e produção textual (La copa del mundo en Brasil; Ser profesor en los dias de hoy, El casamiento gay; Vientre de alquiler; Legalización de las drogas), a maior parte da turma apresentou a preferência pelo tema "Ser profesor en los días de hoy". A seguir, apresentamos a análise do texto produzido pelo aluno PN. Convém esclarecer que os erros ortográficos e gramaticais presentes nas produções escritas analisadas serão mantidos com o objetivo de conservar a sua autenticidade. 


\section{Produção Escrita do aluno PN}

\section{Ser profesor en los días de hoy}

En los días de hoy ser profesor es muy difícil, pero gratificante, es gratificante porque estamos contribuyendo para formación de los alumnos, pasando para elles nostros conocimientos.

En nostro país los recursos económicos son malos administrados por eso la educación tiene quedado un pouco esquecida y con una má calidad educacional. Sin embargo es muy gratificante pasar conocimiento para uno alumno, y desta forma esta contribuyendo para que tengan un futuro mejor.

Con todo el Brasil no esta administrando sus recursos para la educación, para hacer algo mejor para la educación tendrías que invertir $6,3 \%$ de PIB para un bueno crecimiento de sus alumnos.

Para concluir mismo con la mala calidad económica dos recursos para la educación, los profesores tiene orgullo de su profesión y hace lo que esta en su alcance para desenvolver un bueno trabajo y ayudar sus alumnos a tener un futuro promissor.

Figura 1. Artigo de opinião produzido pelo aluno $\mathrm{PN}^{2}$ Fonte: Digitação das autoras do artigo de opinião do aluno PN, 2013.

O texto apresenta características prototípicas do gênero artigo de opinião, isto é, em seu interior é possível localizar a situação-problema, a discussão e a solução - avaliação (BOFF; KÖCHE; MARINELLO, 2009). Na situação-problema, o autor apresentou a questão a ser desenvolvida em seu texto ("En los días de hoy ser profesor es muy dificil, pero gratificante"). Posteriormente, foram expostos os argumentos que sustentaram a tese defendida ("es gratificante porque estamos contribuyendo para formación de los alumnos, pasando para elles nostros conocimientos"; "En nostro país los recursos económicos son malos administrados..."; "el Brasil no esta administrando sus recursos para la educación"). Na solução-avaliação, o autor apresentou suas respostas e apreciações em relação à posição defendida ("es muy gratificante pasar conocimiento para uno alumno"; "mismo con la mala calidad económica dos recursos para la educación, "los profesores tiene orgullo de su profesión"; "hace lo que esta en su alcance para desenvolver un bueno trabajo").

Ao apresentar fatos, dados quantitativos, contradições e argumentos causais, o autor objetivou convencer o leitor a partir do logos, isto é, de argumentos fundamentados na razão. Segundo Perelman e Olbrechts-Tyteca (2005), argumentos que partem de uma situação ou fato atual aumentam o valor do posicionamento defendido pelo autor. Com a utilização dos dados quantitativos, por exemplo, o autor procurou reforçar o valor do seu

\footnotetext{
2 As iniciais dos nomes dos participantes da pesquisa serão utilizadas com a finalidade de preservar suas identidades.
}

argumento e evitar questionamentos por parte do leitor. Sobre esta questão, Oliveira e Nascimento (2008) acrescentam que os números são atrativos e, por fazerem parte da linguagem da precisão, são poucas as pessoas que os questionam. Segundo as autoras, "a crença na objetividade científica dos dados numéricos (matemática, estatística) é que lhes confere alto poder de persuasão" (OLIVEIRA; NASCIMENTO, 2008, p. 10).

A objetividade é uma característica presente na maior parte da sua composição. Entretanto, algumas marcas de subjetividade podem ser localizadas no momento em que o autor se inclui na categoria de professor, ao utilizar o verbo "estar" e o pronome possessivo "nostros", correspondentes a terceira pessoa do plural ("porque estamos contribuyendo para formación de los alumnos, pasando para elles nostros conocimientos"). Além disso, ao se colocar no próprio discurso a partir do uso do verbo "estamos" e do pronome possessivo "nostros", o autor incluiu a leitora do texto que, por sua vez, também é professora.

Foi possível observar que o aluno estabeleceu uma relação objetiva com o leitor, ao optar pelo estilo impessoal e o uso de enunciados assertivos, na maior parte do texto produzido. Esta escolha marca seu estilo como escritor. Segundo Bakhtin (2003), até mesmo a expressividade observada em um enunciado estabelece uma relação com outros enunciados. Nas palavras do autor,

\begin{abstract}
Os enunciados não são indiferentes uns aos outros nem são auto-suficientes; conhecem-se uns aos outros, refletem-se mutuamente. São precisamente esses reflexos recíprocos que lhe determinam o caráter. O enunciado está repleto de ecos, lembranças de outros enunciados, aos quais está vinculado no interior de uma esfera comum da comunicação verbal. O enunciado deve ser considerado acima de tudo como uma resposta a enunciados anteriores dentro de uma dada esfera [...]: refuta-os, confirma-os, completa-os, baseia-se neles, supõe-nos conhecidos e, de um modo ou de outro, conta com eles (BAKHTIN, 2003, p. 316).
\end{abstract}

Ao reconhecer e considerar as relações entre os enunciados da comunicação verbal, Bakhtin chama a atenção para o caráter polifônico presente nos gêneros textuais. A polifonia, como já foi discutida anteriormente, é uma característica inerente ao artigo de opinião. Neste sentido, torna-se importante reconhecer que o discurso do autor apresenta vozes presentes em outros textos. No caso da produção escrita analisada, elementos polifônicos podem ser encontrados, por exemplo, nas estratégias argumentativas escolhidas pelo autor, tais como a apresentação de exemplos, generalizações, dados e fatos que, por sua vez, foram construídas a partir de outras leituras e interações sociais. A marca da objetividade, 
também presente na maior parte do texto, pode ser fruto de experiências de outras vozes.

De acordo com Bakhtin, "a experiência discursiva de qualquer pessoa se forma e se desenvolve em uma interação constante e contínua com os enunciados individuais dos outros" (BAKHTIN, 2003, p. 294). O autor acrescenta que "essas palavras dos outros trazem consigo a sua expressão, o seu tom valorativo que assimilamos, reelaboramos, e reacentuamos" (BAKHTIN, 2003 , p. 294). No caso da produção analisada, traços da experiência discursiva do autor podem aparecer na forma como ele combina e reelabora esse saber compartilhado relativo aos problemas da educação na atualidade, com outros posicionamentos defendidos ao longo do texto. Por exemplo, o contra-argumento de que, mesmo com a má administração dos recursos públicos e a má qualidade da educação, os professores se sentem orgulhosos da sua profissão e realizam um bom trabalho voltado para a formação de seus alunos, pode ser identificado como um discurso reelaborado e reacentuado pelo autor. Ao mesmo tempo, essa visão otimista do autor pode não ser aceita pelos possíveis leitores por não fazer parte de um saber compartilhado e construído acerca da profissão docente na atualidade.

Em outro âmbito de análise, o autor evoca os problemas enfrentados atualmente pela educação ("En nostro país los recursos económicos son malos administrados por eso la educación tiene quedado un pouco esquecida y con una má calidad educacional"), mas age responsivamente no reconhecimento e defesa dos aspectos positivos da profissão docente ("Sin embargo es muy gratificante pasar conocimiento para uno alumno, y desta forma esta contribuyendo para que tengan un futuro mejor"). Como esse argumento foi construído a partir de generalizações apoiadas em pontos de vista pessoais, talvez não compartilhado pelo grupo de possíveis leitores, provavelmente instigue o diálogo e posicionamentos contrários, "porque o enunciado daquele a quem eu respondo (com o qual concordo, ao qual faço objeção, o qual executo, levo em conta, etc.) já está presente, a sua resposta (ou compreensão responsiva) ainda está por vir" (BAKHTIN, 2003, p. 302). E, é justamente nesta "cadeia de comunicação discursiva", que se faz presente sua "atitude responsiva direta" e as "ressonâncias dialógicas" (BAKHTIN, 2003, p. 300).

Em sua produção textual, o aluno também defende argumentos que, de certa forma, são advindos de saberes construídos e compartilhados pelos possíveis leitores do texto. Os posicionamentos defendidos sobre a dificuldade de exercer profissão de docente na atualidade, a má administração dos recursos públicos no Brasil, a má qualidade da educação são procedentes de conhecimentos de mundo oriundos de leituras, interações sociais e informações obtidas em diferentes fontes (rádio, jornal, revistas, televisão) que, de certa forma, são também aceitos e compartilhados por outras pessoas. A seguir, apresentamos a análise do artigo de opinião do aluno AS.

\section{Produção Escrita de AS}

\section{Ser profesor en los días de hoy}

Creo que es una tarea muy difícil ser un profesor. Es necesario tiempo, organización y una fuerza grande para planear las clases y tener éxito con ellas. Aún así, ver una realidad que muchos no están acostumbrados, dónde falta todo en una escuela, y el profesor tiene que usar las metodologías que estudian en la universidad y modificalas.

Además, el profesor tiene que ser muy paciente, pero mantener su rigor y ser un artista, incluso que la enseñanza es el arte de si reinventar. Cabe añadir que él es psicólogo, amigo, orientador y, principalmente, un ejemplo.

¿Y las tecnologías? Bien, ellas deven ser compañeras de los profesores. De esa manera, envolver los alumnos y los da seguridad, pues les gustan el mundo tecnológico.

Así pues, cómo ya he dicho es complicadito ser un profesor- es difícil mismo. Por otro lado, al fin, todos los esfuerzos son muy válidos, pues de la misma manera que el profesor practica la metodología que fue practicada, el alumno aprende más y mejor.

Figura 2. Artigo de opinião produzido pelo aluno AS

Fonte: Digitação da autora do planejamento e artigo de opinião do aluno AS, 2013.

O texto enquadra-se na estrutura prototípica do gênero artigo de opinião, pois apresenta a situação-problema, a discussão e a solução-avaliação dos fatos (BOFF; KÖCHE; MARINELLO, 2009). Na situação-problema, o autor apresenta o 1 - tema do texto ("Creo que es una tarea muy dificil ser un profesor"). Ainda no mesmo parágrafo, é possível localizar o desenvolvimento da tese inicial, a partir das explicações apresentadas no tema ("Es necesario tiempo, organización y una fuerza grande para planear las clases y tener éxito con ellas. Aún así, ver una realidad que muchos no están acostumbrados, dónde falta todo en una escuela, y el profesor tiene que usar las metodologías que estudian en la universidad y modificalas.").

Como estratégias argumentativas, é possível localizar, no texto de AS, generalizações ("el profesor tiene que ser muy paciente, pero mantener su rigor y ser un artista"), definições ("la enseñanza es el arte de si reinventar"; "él es psicólogo, amigo, orientador y, principalmente, un ejemplo."), frases explicativas ("pues les gustan el mundo tecnológico") e contra-argumentos ("Por otro lado, al fin, todos los esfuerzos son muy válidos, pues de la misma manera que el profesor practica la metodología que fue practicada").

Segundo Perelman e Olbrechts-Tyteca (2005), a definição é considerada a expressão de uma identidade, mas também representa uma escolha proveniente de um 
conjunto de outras definições possíveis. Assim sendo, mesmo defendido a partir de diferentes argumentos, o uso da definição é uma tentativa de convencimento na medida em que provoca a reflexão do leitor e levanta questionamentos sobre outras definições que fazem parte do seu conhecimento de mundo.

$\mathrm{Na}$ finalização do texto, AS insistiu na gravidade do fato vinculado à dificuldade de ser professor ("Así pues, cómo ya he dicho es complicadito ser un profesor- es difícil mismo.") e apresenta um contra-argumento que justifica o valor do esforço no exercício da profissão ("Por otro lado, al fin, todos los esfuerzos son muy válidos, pues de la misma manera que el profesor practica la metodología que fue practicada, el alumno aprende más y mejor.").

No que diz respeito ao conteúdo do texto, o aluno apresenta argumentos relacionados a conhecimentos construídos e, talvez, compartilhados por outras pessoas e, até mesmo, pelos possíveis leitores, tais como: a dificuldade inerente à profissão docente, o tempo e esforço demandado pela profissão, a falta de estrutura das escolas, entre outros. Ao discutir sobre o tema, o autor ainda optou pela objetividade em seu discurso ao escolher e utilizar enunciados assertivos, em grande parte do texto (" $\mathrm{el}$ profesor tiene que usar las metodologías que estudian en la universidad"; "el profesor tiene que ser muy paciente, pero mantener su rigor"; "Cabe añadir que él es psicólogo, amigo, orientador $y$, principalmente, un ejemplo").

Segundo Bakhtin (2003), a expressão do enunciado que criamos "é determinada pelos enunciados dos outros sobre o mesmo tema, aos quais respondemos, com os quais polemizamos" (BAKHTIN, 2003, p. 297). No caso, os argumentos criados pelo autor sobre as dificuldades oriundas da profissão docente e as características do professor podem ser entendidos como saberes compartilhados por colegas de profissão, conhecimentos propagados pelas mais diversificadas redes de difusão da informação (rádio, televisão, revistas e jornais) ou afirmações criadas e repetidas que, por sua vez, acabaram transformando-se em "verdades absolutas", aceitas e disseminadas como argumentos característicos do universo da educação brasileira. Esse é o caso, por exemplo, das afirmações utilizadas para definir o professor: psicólogo, amigo, orientador e um exemplo a ser seguido. Segundo Souto Maior (2014), essas definições podem ser entendidas como um tipo de "discurso envolvente", isto é, afirmações "fossilizadas historicamente, retomadas em outros contextos, com significações deslocadas muitas vezes" (SOUTO MAIOR, 2014 , p. 8). No caso da produção escrita analisada, AS defende o argumento de que o professor deve ser um psicólogo, amigo e orientador sem, contudo, refletir criticamente sobre as implicações ideológicas que estão por trás de tais asseverações. As frases fossilizadas são, simplesmente, reproduzidas em seu discurso.
Além do uso de enunciados e argumentos advindos de outras vozes e compartilhados sobre o tema da educação, o autor também mostra aspectos da sua subjetividade na elaboração de posicionamentos, pontos de vista e opiniões sobre o tema discutido. Duas marcas de subjetividade de AS foram localizadas no artigo de opinião analisado. A primeira marca caracterizou o ponto de vista do autor sobre a questão da dificuldade de ser professor ("Creo que es una tarea muy dificil ser un profesor."). A segunda apareceu no final do texto, com a retomada do parecer defendido na

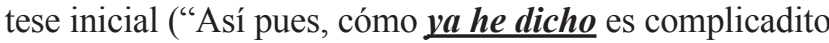
ser un profesor- es difícil mismo"). De acordo com Novaes, Souza e Lima (2008), embora se acredite que a objetividade em um texto não combine com sentimentos e emoções, no processo de produção textual o sujeito também interpreta; e essa interpretação é carregada de "paradigmas, crenças, idiossincrasias, todos impressos, mesmo que nas entrelinhas" (NOVAES; SOUZA; LIMA, 2008, p. 169). No caso do texto analisado, as marcas de subjetividade do aluno advêm de sua atitude valorativa a respeito da profissão docente, construída a partir de suas experiências, histórias, reflexões, discussões, leituras etc. A seguir, apresento a análise da produção escrita do aluno VL.

\section{Produção Escrita de VL}

\section{Ser profesor en los días de hoy}

No es nada fácil ser profesor en la actualidad, pues existen muchos factores que influyen de manera negativa en esta profesión. Veamos algunos factores.

Primeramente, las malas condiciones de trabajo que perjudican directamente el aprendizaje de los estudiantes. Con respecto a ese punto, podemos observar muchas escuelas sin las mínimas condiciones de trabajo, o sea, algunas instituciones no tiene, ni siquiera, sillas o baños decentes.

En segundo lugar, resalto los bajos suelos de los profisionales de la educación, que desde hace muchos años están en una lucha constante por reconocimiento y valoración de su profesión y por consecuencia, mejores sueldos.

Además, la falta de interés y desmotivación de los estudiantes es un tema muy delicado y que no puede ser ignorado por los que hacen la educación, ya que es fundamental para el aprendizaje. Cabe añadir que la desmotivación es una de las causas principales de la evasión escolar.

Hay que tener en cuenta que delante de todos esos problemas citados, es complicado ser profesor, por ejemplo, en países como el Japón, los profesores son valorados, respetados y, encima, ganan un sueldo digno de su profesión.

Delante de este cuadro aquí mostrado, hago una pregunta: ¿Aún así vale la pena ser profesor? A mi entender sí, puesto que, como dice la lingüista Rita Zozzoli en uno de sus artículos - "(...) más que educador digno de ese nombre puede abrir mano da utopía?" - puede parecer que la situación en que viven los educadores nunca va a cambiar o es una utopía, pero si nosotros que hacemos la educación en nuestro país no creemos en eso, decisivamente nunca cambiará.

Figura 3. Artigo de opinião produzido pelo aluno VL Fonte: Digitação da autora do planejamento e artigo de opinião do aluno VL, 2013. 
O texto possui características prototípicas do gênero artigo de opinião, já que apresenta a situação-problema, a discussão e a solução-avaliação dos fatos (BOFF; KÖCHE; MARINELLO, 2009). Como ponto inicial, o autor apresentou o $1^{\mathrm{O}}$ tema do texto, como a situaçãoproblema a ser discutida ("No es nada fácil ser profesor en la actualidad, pues existen muchos factores que influyen de manera negativa en esta profesión."). Os argumentos que fundamentam o tema foram desenvolvidos a partir de diferentes estratégias argumentativas ao longo do texto. Ao discutir sobre o problema apontado na tese inicial, o aluno utilizou exemplos ("podemos observar muchas escuelas sin las mínimas condiciones de trabajo"; "por ejemplo, en países como el Japón, los profesores son valorados, respetados"), fatos ("los bajos suelos de los profisionales de la educación, que desde hace muchos años están en una lucha constante por reconocimiento y valoración de su profesión"), generalizações ("la falta de interés y desmotivación de los estudiantes es un tema muy delicado"), comparações ("en países como el Japón, los profesores son valorados, respetados y, encima, ganan un sueldo digno de su profesión"), argumento de autoridade ("la lingüista Rita Zozzoli en uno de sus artículos - (...) más que educador digno de ese nombre puede abrir mano da utopía?").

Segundo Perelman e Olbrechts-Tyteca (2005), o argumento de autoridade serve para complementar uma rica argumentação e seu espaço no texto argumentativo é considerável. Os autores acrescentam que "quanto mais importante é a autoridade, mais indiscutíveis parecem suas palavras" (PERELMAN; OLBRECHTS-TYTECA, 2005 , p. 351). No caso, o aluno citou a linguista Rita Zozzoli como estratégia argumentativa para reforçar sua ideia de que, ainda que a profissão de professor seja difícil, vale a pela. As palavras de uma linguística importante e reconhecida validam e dão força aos seus argumentos, podendo torná-los quase que inquestionáveis.

Em outro enfoque de análise, Bazerman (2007) defende o posicionamento de que as citações são mecanismos linguísticos que servem para encaixar a "linguagem na interação social e nas relações sociais" (BAZERMAN, 2007, p. 95). Nessa perspectiva, ao citar a linguísta Zozzoli, o aluno não só reforça o poder da sua argumentação, mas também interage e estabelece um diálogo com a autora. Ele interpreta seu discurso e concorda com o argumento de que o professor não deve perder a utopia. Por meio do "diálogo social" (BAZERMAN, 2007, p. 95) estabelecido com a autora, o aluno se apoia em suas palavras e as utiliza em seu texto. Ao fazer isso, assume uma "ativa posição responsiva" (BAKHTIN, 2003, p. 291) de concordância com a autora citada. Além disso, quando combina a citação de Zozzoli com as crenças pessoais e posicionamentos defendidos acerca da profissão docente, o aluno representa sua expressividade, pois "experiência discursiva individual de qualquer pessoa se forma e se desenvolve em uma interação constante e contínua com os enunciados individuais dos outros" (BAKHTIN, 2003, p. 294).

$\mathrm{Na}$ solução-avaliação, o aluno lançou um questionamento ("¿Aún así vale la pena ser profesor?") e se posicionou diante do tema proposto para reflexão (" $A$ mi entender sí, puesto que, como dice la lingüista Rita Zozzoli en uno de sus artículos..."). O texto foi finalizado com a apresentação do posicionamento do autor diante do questionamento levantado e do argumento de autoridade utilizado para validar seu ponto de vista ("puede parecer que la situación en que viven los educadores nunca va a cambiar o es una utopía, pero si nosotros que hacemos la educación en nuestro país no creemos en eso, decisivamente nunca cambiará.").

Ainda no que diz respeito à produção analisada foi possível observar que o autor manteve a objetividade na produção textual em questão. Apenas duas marcas de subjetividade foram encontradas no último texto produzido. Na primeira, o autor ressalta o problema relacionado ao baixo salário dos professores (" educación”). Na segunda marca, assume sua posição na defesa do argumento de que os profesores precisam acreditar na mudança da situação vivenciada pelos professores (" $\underline{A}$ mi entender sí, puesto que, como dice la linguista Rita Zozzoli en uno de sus artículos (...) pero si nosotros que hacemos la educación en nuestro país no creemos en eso, decisivamente nunca cambiará.).

Em relação ao último argumento ("pero si nosotros que hacemos la educación en nuestro país no creemos en eso, decisivamente nunca cambiará"), é interessante observar que o autor relacionou-se com o leitor do texto, ao incluí-lo na própria argumentação, a partir do uso do pronome pessoal, em terceira pessoa "nosotros".

Nesse sentido, apesar de algumas inadequações observadas em relação aos aspectos estruturais da língua, foi possível observar que o ensino explícito de estratégias argumentativas, de fato, contribuiu para a produção de artigos de opinião em língua espanhola. Os participantes da pesquisa demonstraram utilizar não só argumentos, mas também contra-argumentos para defender suas ideias e posicionamentos diante do tema proposto para produção textual. Conhecimentos de mundo, crenças e valores estiveram presentes como discursos construídos a partir de diferentes vozes, experiências e leituras anteriores. Esses fatores evidenciam a importância do trabalho sistematizado com gêneros textuais e argumentação no ensino de línguas. 


\section{Considerações finais}

A pesquisa realizada possibilitou-nos verificar, a partir de uma sequência didática de ensino-aprendizagem da escrita argumentativa em língua espanhola, que os alunos de Letras, ainda nas fases introdutórias da aprendizagem, são capazes de produzir artigos de opinião no idioma espanhol, se planejarem previamente suas ideias, conhecerem a estrutura do gênero e utilizarem adequadamente as estratégias argumentativas e elementos retóricos. Essa evidência contradiz a ideia de que para produzir textos é necessário que antes se domine, de maneira efetiva, o código linguístico.

No que diz respeito ao aspecto estrutural dos gêneros analisado, pode-se dizer que, de um modo geral, os participantes da pesquisa não apresentaram dificuldades quanto ao formato prototípico característico do artigo de opinião. Quanto à análise textual e retórica dos textos, é também possível afirmar que os alunos refletiram e se posicionaram criticamente diante do tema escolhido para leitura, discussão e produção escrita em língua espanhola. Para tanto, reuniram argumentos, contraargumentos, exemplos, generalizações e outras técnicas argumentativas, no intuito de defender suas ideias e posicionamentos diante do mundo.

Nesse sentido, torna-se possível afirmar que ao escrever, os alunos expressaram suas emoções, questionaram seu leitor, expuseram seus sentimentos, interagiram com outros autores e diferentes leituras. Essa é uma forma de entender a escrita enquanto ação social e não somente como uma atividade individual implicada na reunião e organização correta de elementos linguísticos para a elaboração de frases, períodos e orações (LANKSHEAR; KNOBEL, 2011).

Além disso, os participantes da pesquisa também empreenderam e construíram sentidos em seus textos escritos, socializando pensamentos, ideias, argumentos e intenções de diferentes maneiras (BAZERMAN, 2007). Elementos linguísticos e estratégias argumentativas foram escolhidos a fim de compartilhar ideias e defender posições assumidas diante dos temas propostos para discussão. Isto, nada mais é, do que uma forma de agir no mundo e interagir com as pessoas, mediante a prática da escrita.

Ao questionarem o possível leitor, utilizarem elementos linguísticos que marcam a objetividade requerida pelo gênero textual ou empregarem enunciados exortativos com a finalidade de dialogar com o possível leitor, os alunos indicaram que, mais do que apenas reunir elementos linguísticos para produzir ideias e argumentos, por meio da escrita, há uma relação de interação com aquele para o qual o texto será direcionado. Nessa relação, os escritores imaginam esse leitor, questionam suas atitudes e dialogam com ele.
As escolhas dos argumentos, das estratégias de articulação das informações, dos elementos retóricos para posicionar-se e defender suas ideias constituem-se, assim, como parte do repertório individual do aluno de conhecimentos construídos e acumulados ao longo da sua existência. Segundo Bazerman (2007), as produções textuais incorporam muitas vozes provenientes de interações anteriores. Estas vozes incluem palavras, perspectivas, ideias, humores, formas e padrões organizacionais com os quais o escritor cruzou em algum momento da sua vida e às quais respondeu.

Assim sendo, é possível concluir que, apesar os deslizes linguísticos observados nos textos analisados, os resultados da pesquisa revelaram que os alunos são capazes de produzir textos argumentativos em língua espanhola ainda nas fases iniciais de sua aprendizagem. Tal fator evidencia a importância da sistematização do ensino da escrita, a partir de sequências didáticas voltadas para o trabalho com gêneros textuais, desde o início da aprendizagem do idioma.

\section{Referências}

ANTUNES, A. Análise de textos: fundamentos e práticas. São Paulo: Parábola, 2010.

BAKHTIN, M. Estética da criação verbal. São Paulo: Martins Fontes, 2003.

BOFF, O. M. B.; KÖCHE, V. S.; MARINELLO, Adiane F. $\mathrm{O}$ gênero textual artigo de opinião: um meio de interação. ReVEL: Revista Virtual de Estudos da Linguagem, v. 7, n. 13, 2009. Disponível em: <http://www.revel.inf.br/files/artigos/ revel_13_o_genero_textual_artigo_de_opiniao.pdf $>$. Acesso em: $2 \overline{2}$ jan. 2014.

BRONCKART, J-P. Atividade de linguagem, textos e discursos: por um interacionismo sociodiscursivo. Trad. Anna Rachel Machado e Péricles Cunha. São Paulo: EDUC, 1999.

FEITOZA, C. J. A; MENDES, M. H. P. Um estudo do gênero artigo de opinião: procedimentos para torna-lo um objeto ensinável. Horizontes, Itatiba, v. 28, n. 2, p. 51-61,jul./dez. 2010. Disponível em: <http:/webp.usf.edu.br/itatiba/mestrado/educacao/ uploadAddress $/ 5$-Um $\% 20$ estudo $\% 20$ do $\% 20$ g\%C $3 \%$ A Anero $\% 20$ artigo $\% 20$ de $\% 20$ opini\%C3\%A30\%20-\%20 procedimentos $\% 20$ para $\% 20$ torn $\%$ C3\%A $1-10 \% 20$ um $\% 20$ objeto $\% 20$ ensin $\%$ C3\%A1vel[17030].pdf>. Acesso em: $16 \mathrm{fev}$. 2014.

MARCUSCHI, L. A. Produção textual, análise de gêneros e compreensão. São Paulo: Parábola, 2008.

MENICONI, F. C. A Progressão Temática em Produções Escritas de Alunos de Espanhola com Língua Estrangeira. Revista Eletrônica Via Litterae, v. 2, p. 416-434, 2010. Disponível em: <http://www2.unucseh.ueg.br/vialitterae/assets/ files/vl_v2_v2/8-13 A_progressao_tematica_em_producoes escritas_espanhol_LE-FLAVIA_C_MENICONI. em: 27 jan. 2014.

MENICONI, F. C. O ensino da produção escrita para alunos iniciantes no aprendizado da língua espanhola: uma 
pesquisa-ação no curso de letras. Maceió: UFAL, 2015. 263 f. Tese (Doutorado em Letras e Linguística) - Programa de Pós-Graduação em Letras e Linguística, Faculdade de Letras, Universidade Federal de Alagoas, Maceió, 2015.

MEYER, M. A retórica. São Paulo: Ática, 2007.

NOVAES, V. R.; SOUZA, G. M. C.; LIMA, D. F. A subjetividade de estudantes em suas relações com a escrita: um estudo exploratório. Ciências \& Cognição, Rio de Janeiro, v. 13, n. 3, p. 162-171, 2008. Disponível em: <http://www. cienciasecognicao.org/pdf/v13_3/m318246.pdf $>$. Acesso em: 5 ago. 2014.

OLIVEIRA, E. G.; NASCIMENTO, S. S. O numeral como fator de persuasão no discurso da publicidade. Tabuleiro de Letras, Salvador, v. 1, n. 1, 2008. Disponível em: <http:// www.tabuleirodeletras.uneb.br/secun/numero_01/pdf/artigo vol01_01.pdf>. Acesso em: 1 dez. 2014.

PERELMAN, C.; OLBRECHTS-TYTECA, L. Tratado da argumentação: a nova retórica. 2. ed. São Paulo: Martins Fontes, 2005.

REBOUL, O. Introdução á retórica. São Paulo: Martins Fontes, 1998.
SANTOS, M. C.; MELO, M. F. A utilização da sequência didática para a construção da argumentação no artigo de opinião. RBPG, Brasília, DF, v. 8, supl. 2, p. 619-635, 2012. Disponível em: <http://www2.capes.gov.br/rbpg/images/ stories/downloads/RBPG/Vol.8_suplemento2/capitulo11.pdf $>$. Acesso em: 16 fev. 2014.

SOUTO MAIOR, R. Implicações do ensino da produção textual em sala de aula: os discursos envolventes e a escrita contemporânea. In: SIMÕES, D. M. P.; FIGUEIREDO, F. J. Q. de (Org.). Metodologia em/de linguística aplicada para o ensino e aprendizagem de línguas. Campinas: Pontes, 2014. p. 7-285.

UBER, T. J. B. Artigo de opinião: estudos sobre um gênero discursivo. Maringá: Universidade Estadual de Maringá: 2008. Disponível em: <http://www.diaadiaeducacao.pr.gov.br/portals/ pde/arquivos/255-4.pdf > . Acesso em: 20 jan. 2014.

THIOLLENT, M. Metodologia da pesquisa-ação. São Paulo: Cortez: Autores Associados, 1986. 108 p.

Recebido: 19 de agosto de 2015

Aprovado: 05 de dezembro de 2015

Contato: flaviacolen@globo.com mimatoso@uol.com.br 